\title{
Acute Hemorrhagic Edema of Infancy
}

National Cancer Institute

\section{Source}

National Cancer Institute. Acute Hemorrhagic Edema of Infancy. NCI Thesaurus. Code C113749.

A self-limiting cutaneous vasculitis that typically presents as a clinical triad of purpura, edema, and fever in children between the ages of four months and two years old. It is usually associated with a recent history of upper respiratory infection and/or antibiotic therapy. 